\title{
IDENTIFIKASI MUSIM PRODUKTIF RUMPUT LAUT Eucheuma striatum DI PERAIRAN GORONTALO UTARA
}

\author{
Pustika Ratnawati ${ }^{\#}$ dan Petrus Rani Pong-Masak \\ Loka Riset Budidaya Rumput Laut \\ (Naskah diterima: 13 Desember 2017; Revisi final: 13 April 2018; Disetujui publikasi: 13 April 2018)
}

\begin{abstract}
ABSTRAK
Minimnya informasi di tingkat pembudidaya mengenai waktu tanam yang produktif sesuai spesifikasi lokasi dan perubahan musim membuat produktivitas lahan dikelola kurang optimal. Identifikasi terkait dengan musim optimal dalam pemanfaatan lahan secara produktif sebagai bagian dari manajemen budidaya perlu dilakukan. Tujuan penelitian ini adalah untuk menentukan musim produktif rumput laut Euchuema striatum di wilayah perairan Teluk Langge, Gorontalo Utara. Penelitian dilakukan pada bulan JanuariDesember 2015 di Desa Langge, Kabupaten Gorontalo Utara. Unit percobaan disusun dengan rancangan acak kelompok pada tiga zona lokasi budidaya sebagai perlakuan, dengan tiga kali ulangan. Zona-1 berdekatan dengan daratan (jarak: 100-200 m), zona-2 dengan estimasi jarak 500-600 m, dan zona-3 di bagian ujung teluk dengan jarak 1.000-1.500 m dari daratan utama. Indikator utama yang diamati adalah pertumbuhan, penyakit, dan kualitas perairan. Rumput laut Eucheuma striatum yang dibudidaya dengan metode longline dengan bobot awal tanam $50 \mathrm{~g} / \mathrm{rumpun}$ dan panjang tali ris $35 \mathrm{~m}$. Pada setiap bentangan diberi penanda/label sebanyak 10 titik dan dilakukan pengamatan setiap interval waktu 45 hari. Hasil pengamatan selama tujuh siklus budidaya menunjukkan bahwa musim produktif rumput laut $\mathrm{E}$. striatum di perairan Teluk Langge terjadi pada bulan Juni hingga September. Pertumbuhan rumput laut terbaik pada kawasan budidaya adalah yang dekat dengan daratan.
\end{abstract}

\section{KATA KUNCl: Eucheuma striatum; musim produktif; Teluk Langge \\ ABSTRACT: Identification of productive season for seaweed Eucheuma striatum in Langge Bay North Gorontalo. By: Pustika Ratnawati and Petrus Rani Pong-Masak}

Limited information available to seaweed farmers regarding the optimum planting time at a certain location and adaptation to seasonal changes contributed to low seaweed productivity. Therefore, an accurate planting calendar to optimize the use of productive coastal areas is vitally needed as part of the sustainable management of seaweed cultivation. The purpose of this study was to identify the productive season for Euchuema striatum in the Langge Bay water, North Gorontalo. The study was conducted from January to December 2015 in the Langge Village, North Gorontalo Regency. The experiment units consisted of three farming zonetreatments with three replicates arranged in a block randomized design. Each farming zone was situated perpendicular to and at a certain distance from the shoreline (zone- $1=100-200 \mathrm{~m}$, zone-2 $=500-600 \mathrm{~m}$, and zone- $3=1,000-1,500 \mathrm{~m}$ ). The main variables measured were growth, disease occurrence, and water qual ity. Eucheuma striatum seeds were cultivated using a long-line method which the length of the main ropes used was $35 \mathrm{~m}$ and the initial seed weight was $50 \mathrm{~g}$. Along each of the main rope, 10 seeds were marked, labelled and observed at every culture cycle (45 days) and lasted for 7 cycles. The results of observation suggested that the productive season for $\mathbf{E}$. striatum is from June to November. The best area for an optimum seaweed growth in the study region is on the area close to the shoreline (zone-1).

KEYWORDS: Eucheuma striatum; productive season; Langge Bay

\footnotetext{
\# Korespondensi: Loka Riset Budidaya Rumput Laut. Jl. Pelabuhan Etalase Perikanan, Dusun Pohilihe Desa Tabulo Selatan Kec. Mananggu kab. Boalemo 96265, Gorontalo, Indonesia.

E-mail: ratnawatipustika@gmail.com
} 


\section{PENDAHULUAN}

Provinsi Gorontalo memiliki sentral budidaya rumput laut di kawasan Kabupaten Gorontalo Utara. Kabupaten Gorontalo Utara merupakan daerah minapolitan yang dikembangkan berdasarkan Keputusan Bupati Nomor 153 tahun 2008 dengan luas kawasan budidaya laut sekitar 6.400 ha (Kamuli, 2014). Komoditas unggulan minapolitan adalah rumput laut dan udang, dengan kenaikan produksi di setiap tahunnya berkisar 15\%20\% (BPS Gorontalo Utara, 2014).

Wilayah pengembangan rumput laut difokuskan di wilayah Kecamatan Anggrek yang meliputi perairan Desa Langge dan Desa Popalo. Perairan Teluk Langge secara geografis berada di bagian utara dengan posisi yang menjo rok ke daratan utama, serta dikelilingi oleh perbukitan. Gorontalo Utara ditetapkan menjadi kawasan minapolitan perikanan tangkap dan budidaya laut dengan komoditas rumput laut, udang, dan kerapu (Kamuli, 2014).

Minimnya informasi di tingkat pembudidaya mengenai penentuan pola yang terkait dengan musim produktif, membuat pembudidaya tidak bisa menentukan musim tanam yang tepat. Salah satu contoh adalah terjadinya penyakit ice-ice, oleh karena itu, kondisi lingkungan perairan perlu pengamatan yang dilakukan secara sistematis untuk mengurangi dampak kegagalan panen. Kajian terkait pengembangan wilayah yang meliputi zonasi, pola tanam, dan kebijakan daerah merupakan aspek dalam mengoptimalkan produksi rumput laut di masa yang akan datang (Parenrengi \& Sulaeman, 2007).

Sampai saat ini sebagian pembudidaya menggunakan jenis Kappaphycus alvarezii karena dianggap lebih mudah dan menguntungkan. Permasalahan yang mulai muncul di tingkat pembudidaya adalah terjadinya penurunan produksi rumput laut karena beberapa faktor, seperti ketidaktahanan terhadap perubahan perairan dan rendahnya mutu rumput laut.

Pertumbuhan rumput laut dipengaruhi oleh lokasi, musim tanam, dan varietas yang dibudidayakan. Pemilihan spesies lain penghasil karaginan merupakan alternatif dalam meningkat produksi. Kelompok alga merah (Rhodophyta) adalah penghasil karaginan yang dikenal seperti Kappaphycus alvarezii, Eucheuma denticulatum, dan Eucheuma striatum (Utomo, 2011).

Penentuan musim tanam optimum dan faktor lingkungan perairan yang berpengaruh perlu dilakukan (Nurdjana, 2006). Hasil observasi diharapkan berguna untuk mendukung peningkatkan produksi rumput laut dengan pemanfaatan Iahan secara produktif. Tujuan penelitian ini adalah untuk menentukan musim produktif rumput laut Eucheuma striatum di wilayah perairan Teluk Langge, Gorontalo Utara.

\section{BAHAN DAN METODE}

\section{Lokasi dan Waktu Penelitian}

Penelitian dilaksanakan di perairan Desa Langge tepatnya di sekitar Teluk Langge, Kabupaten Gorontalo Utara, Provinsi Gorontalo. Pengamatan dan identifikasi parameter uji dilakukan pada bulan Januari hingga Desember 2015 (Gambar 1).

\section{Desain Penelitian}

Penelitian dilakukan selama tujuh siklus tanam dengan pengamatan setiap 45 hari secara kontinu. Desain penelitian menggunakan rancangan acak kelompok dengan perlakuan adalah lokasi penempatan unit budidaya longline (tali panjang) pada lokasi yang berbeda dengan tiga kali ulangan. Penempatan unit budidaya terbagi menjadi tiga zona yang disesuaikan dengan lokasi budidaya yang dimiliki oleh pembudidaya rumput laut.

Zona pertama dekat daratan dengan estimasi jarak jarak sekitar 100-200 m. Pada zona dua mengarah ke bagian tengah dan semakin menjauh dengan daratan dengan estimasi jarak 500-600 m, dan yang terakhir zona ketiga yang berada di bagian ujung teluk dengan jarak sekitar 1.000-1.500 m dari daratan utama.

Rumput laut Eucheuma striatum diperoleh dari pembudidaya di sekitar lokasi penelitian. Penanaman rumput laut dilakukan pada tali ris berukuran panjang 35 m dengan kapasitas 230 rumpun. Bobot awal rumput laut sebesar $50 \mathrm{~g} /$ rumpun dan bibit yang digunakan adalah ujung-ujung talus muda. Tali ris diikat pada tali utama wadah longline (Gambar 2).

Pengukuran pertumbuhan rumput laut dilakukan dengan cara menimbang bobot rumput laut per rumpun yang telah diberi label. Data produksi diestimasi pada setiap lokasi dan unit budidaya dengan penimbangan total bobot basah per tali ris/bentangan pada saat panen.

\section{Pengumpulan Data Primer dan Sekunder}

Kualitas lingkungan perairan diukur pada tiga zona titik penelitian, dengan pengambilan secara in-situ setiap 15 hari pada pagi hari yang meliputi: suhu $\left({ }^{\circ} \mathrm{C}\right)$ dan salinitas (ppt) Pengukuran kimia perairan secara dan ex-situ dilakukan pada saat musim produktif yang meliputi: nitrat (mg/L) dan fosfat (mg/L).

Pengumpulkan data primer untuk identifikasi musim produktif rumput laut dilakukan dengan mengamati beberapa parameter yaitu: pertumbuhan, morfologi (warna dan ukuran talus), penyakit ice-ice, 

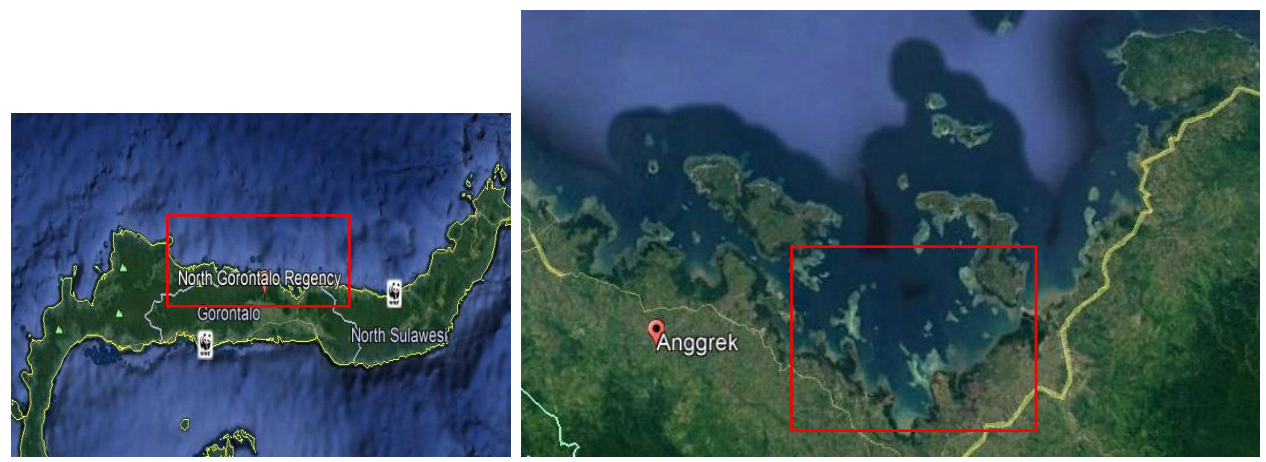

Gambar 1. Kawasan perairan Teluk Langge, Gorontalo Utara

Figure 1. Langge Bay waters, North Gorontalo

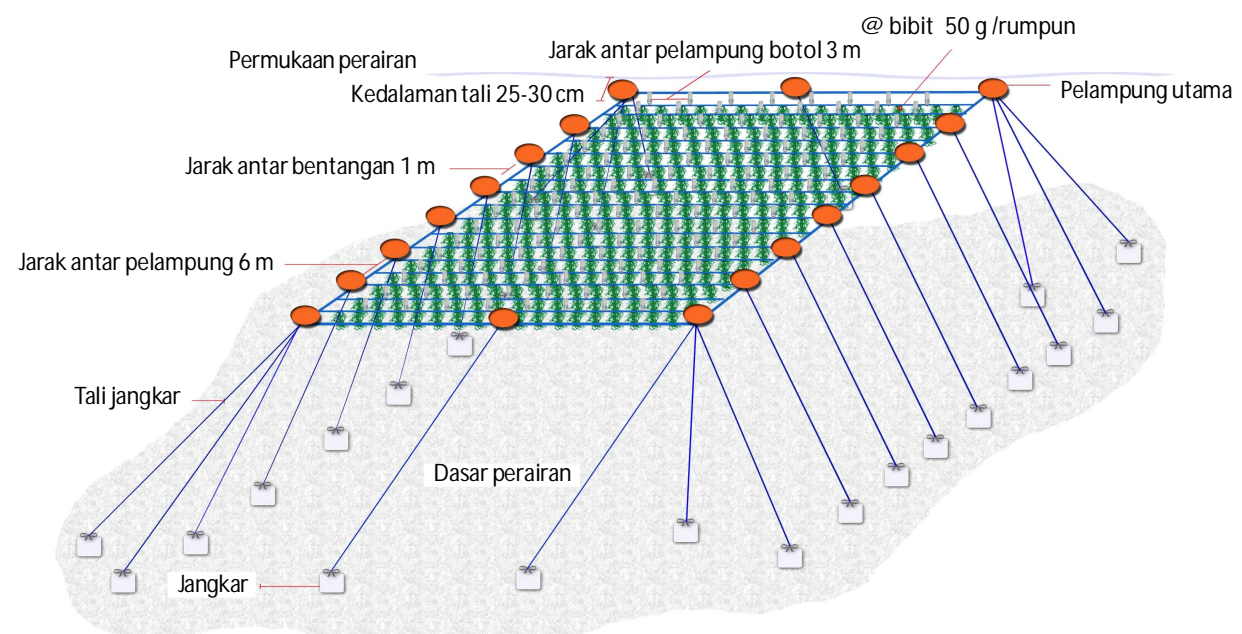

Sumber (Source): Pong-Masak (2015)

Gambar 2. Metode budidaya longline yang banyak digunakan oleh pembudidaya di Teluk Langge.

Figure 2. Longline methods commonly used by farmer at Langge bay.

(teritip, epifit, dan bulu tikus), suspensi/partikel, dan musim (penghujan dan kemarau).

Pengumpulan data sekunder dilakukan dengan mencari data dukung berupa data curah hujan dari BMKG. Data-data yang diperoleh dianalisis secara statistik dan dibahas untuk menentukan musim produktif berdasarkan pertumbuhan rumput laut pada setiap siklus budidaya.

\section{Analisis Data}

Pengamatan pertumbuhan rumput laut dan kualitas perairan dilakukan setiap siklus (45 hari) hingga tujuh siklus tanam. Data dianalisis sidik ragam (ANOVA) dengan uji lanjut Scheffe yang diolah menggunakan SPSS 16.0 untuk melihat efek perbedaan perlakuan. Pengukuran pertumbuhan dihitung dengan menganalisis laju pertumbuhan harian dengan rumus (Effendi, 2003):

$$
\mathrm{LPH}=\frac{\left(\ln W \mathrm{t}-\ln \mathrm{Wo}_{0}\right)}{\mathrm{t}} \times 100
$$

di mana:

$\mathrm{LPH}=$ laju pertumbuhan harian (\%hari)

$\mathrm{Wt}=$ bobot rata-rata pada waktu ke-t $(\mathrm{g})$

$W_{0}=$ bobot rata-rata awal $(\mathrm{g})$

$\mathrm{t}=$ waktu (hari) 


\section{HASIL DAN BAHASAN}

Pengukuran laju pertumbuhan rumput laut pada siklus-1 (Januari-Maret) tidak dapat dilakukan karena gagal panen, disebabkan terjadinya banjir (Gambar 4). Curah hujan tinggi pada awal tahun meningkatkan suplai air tawar dan material daratan yang terbawa ke laut menyebabkan banyak rumpun yang jatuh dan hanyut karena tersangkut sampah atau material dari daratan.

Memasuki siklus-2 pada bulan Maret-April laju pertumbuhan tertinggi hanya mencapai $0,8 \%$ hari (zona-3). Pada zona-1 dan zona-2 memiliki pertumbuhan di bawah 1\% 1 hari. Meningkatnya suhu perairan hingga $32^{\circ} \mathrm{C}$ dan berkurangnya curah hujan hingga > $100 \mathrm{~mm}$ menjadi indikasi rumput laut tidak tumbuh secara optimal.

Rendahnya laju pertumbuhan E. striatum juga disebabkan beberapa talus terserang ice-ice, teritip, dan lumpur (Gambar 3) sehingga talus patah dan jatuh. Perubahan kondisi lingkungan membuat rumput laut stres, sehingga terjadi perubahan warna talus menjadi pucat dan semakin memutih dan akhirnya membusuk. Infeksi ice-icemenyerang kebagian pangkal, batang, dan ujung talus muda dengan penyebaran secara vertikal (dari bibit) atau horizontal melalui perantara air (Santoso \& Nugraha, 2008).

Memasuki periode siklus ke-3 mulai terjadi peningkatan pertumbuhan dengan rata-rata $\mathrm{LPH} 2,4 \%$ hari pada zona-1, dan LPH 2,3\% hari pada zona-2. Hasil uji lanjut memperlihatkan pertumbuhan pada siklus-3 berbeda nyata $(P<0,05)$ antara zona-1 dengan zona-3 (LPH 1,4\%hari).

Periode tanam siklus-4 juga menunjukan tren peningkatan pertumbuhan yang terjadi ditiga zona budidaya. Perhitungan LPH tertinggi pada zona-1 (4,1\%/ hari) diikuti dengan zona-2 dengan LPH 3,6\% /hari dan yang terendah sebesar 2,9\%/hari di zona-3. Menurut
Anggadiredja et al. (2011), bahwa pertumbuhan rumput laut dikatakan baik bila laju pertumbuhan hariannya (LPH) tidak kurang dari 3\%hari.

Pertumbuhan rumput laut E. striatum mengalami puncaknya pada perio de Juli hingga September dengan pertumbuhan tertinggi mencapai 4,6\%/hari pada zona1 sedangkan untuk zona-2 dan zona-3 mengalami penurunan pertumbuhan dengan LPH akhir 2,9\% Hasil ini menunjukkan adanya perbedaan yang signifikan $(P<0,05)$ terhadap pertumbuhan rumput laut pada zona-1. M eningkatnya pertumbuhan pada zona1 dipengaruhi oleh kondisi perairan pada zona-1, di mana terjadi penurunan suhu dari $30^{\circ} \mathrm{C}$ menjadi $28^{\circ} \mathrm{C}$ dan peningkatan salinitas dari 33 ppt menjadi $35 \mathrm{ppt}$.

Terjadinya penurunan suhu perairan (Gambar 5) disebabkan oleh intensitas cahaya dan sirkulasi udara yang rendah di perairan. Kisaran suhu perairan selama musim produktif yaitu $28^{\circ} \mathrm{C}-30^{\circ} \mathrm{C}$. Menurut Erlania \& Radiarta (2014), melaporkan musim produktif untuk budidaya Kappaphycus striatum di Teluk Gerupuk terjadi pada bulan Juli-Oktober dengan suhu optimum pada kisaran $26^{\circ} \mathrm{C}-29^{\circ} \mathrm{C}$, biasanya rumput laut jenis Eucheuma dapat tumbuh dengan kisaran suhu antara $26^{\circ} \mathrm{C}-30^{\circ} \mathrm{C}$ (Anggadiredja et al., 2011).

Pada periode siklus enam bulan September-November terjadi penurunan laju pertumbuhan yang cukup signifikan di setiap lokasi pengamatan, di mana rumput laut hanya tumbuh pada zona-1 (LPH 1,8\%/hari) yang dekat dengan daratan. Hasil uji lanjut menunjukkan berbeda nyata $(\mathrm{P}<0,05)$ dengan pertumbuhan pada zona-2. Hal tersebut berlanjut hingga siklus-7 pada bulan November-Desember, laju pertumbuhan semakin menurun di tiga zona budidaya akibat banyak rumput laut yang mati. Tingkat kelangsungan hidup pada zona-1 lebih baik dibandingkan zona-2 dan zona-3 dikarenakan posisi yang lebih dekat dengan daratan yang masih memungkinkan adanya suplai air tawar.

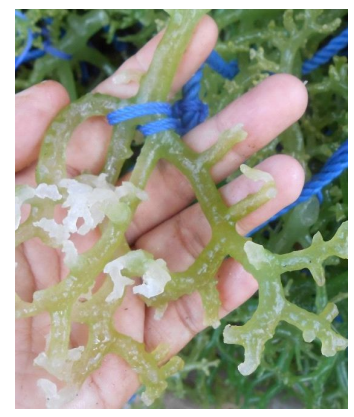

(a)

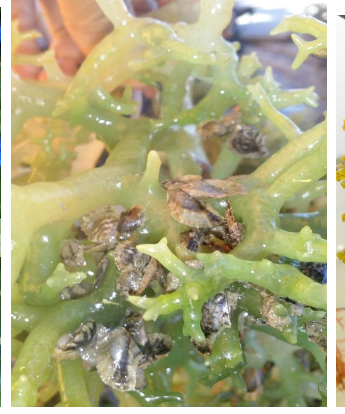

(b)

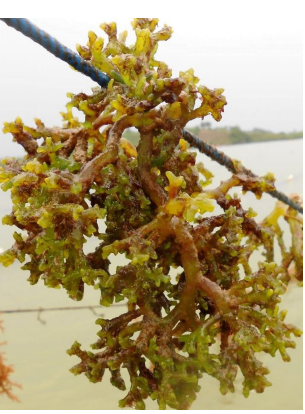

(c)

Gambar 3. Talus yang terserang ice-ice (a), teritip (b), dan lumpur (c).

Figure 3. Damaged thallus due to iceice (a), barnacles (b), and mud (c). 
6

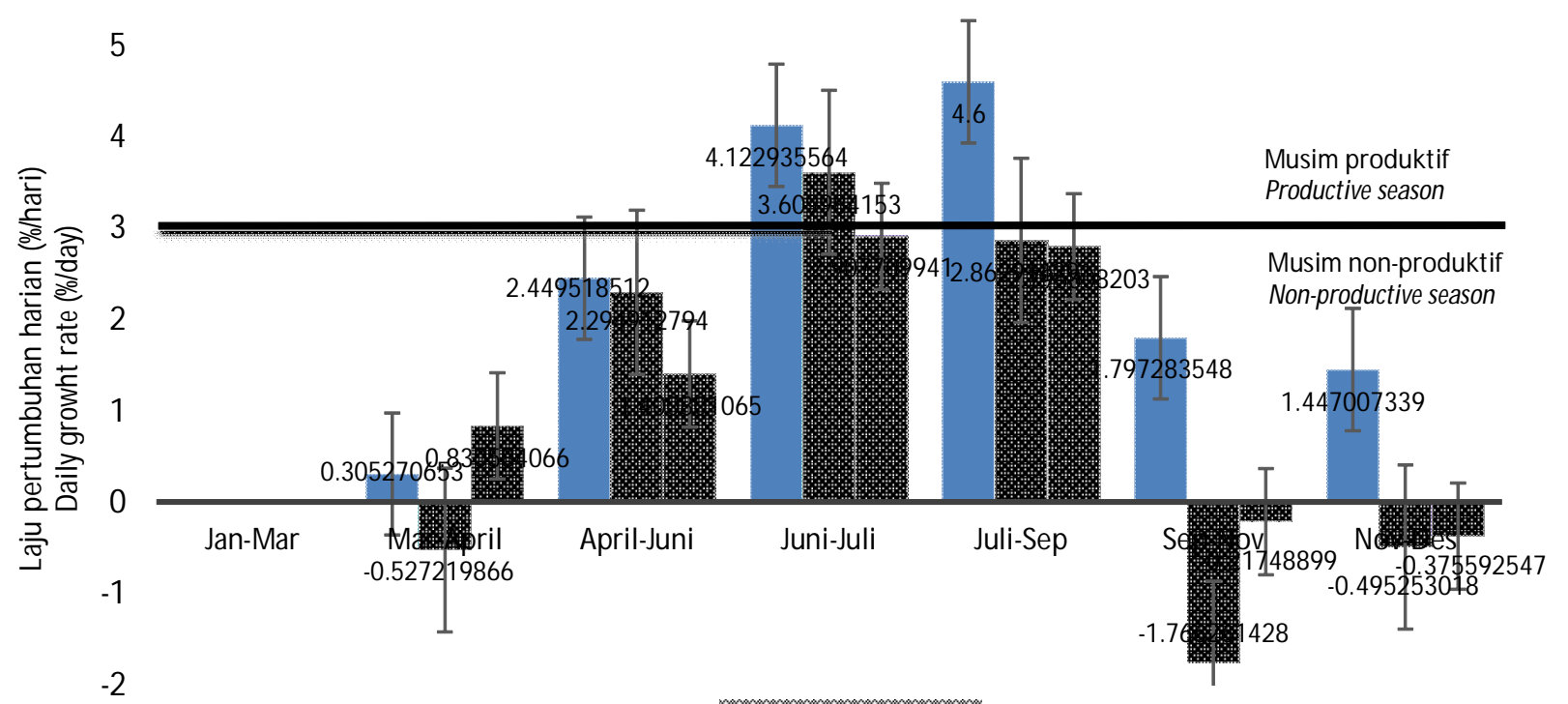

$1:=1:=1:-1$

Gambar 4. Rataan laju pertumbuhan harian rumput laut E. striatum selama tujuh periode budidaya di Teluk Langge, Gorontalo Utara ( $X=$ zona- $1 ; Y=$ zona-2; $Z=$ zona- 3 ).

Figure 4. Average daily growth rate of $\mathbf{E}$. striatum during the seven cultivation periods in Langge Bay, North Gorontalo ( $X=$ zone-1; $Y=$ zone-2; $Z=$ zone-3).

Pada siklus ini terjadi serangan ice-ice di semua lokasi pengamatan yang menyebabkan kematian bahkan kegagalan panen. Munculnya ice-ice diduga karena perubahan lingkungan perairan akibat peningkatan salinitas mencapai 35 ppt dan suhu perairan. Perubahan lingkungan membuat rumput laut stres dengan munculnya lendir dari talus dan memacu pertumbuhan bakteri (Hurtado \& Agbayani, 2000). Gejala yang diperlihatkan adalah pertumbuhan yang lambat, terjadinya perubahan warna pada talus yang kemudian menjadi putih dan busuk (Santoso \& Nugraha, 2008) sehingga terjadi penurunan bobot secara keseluruhan.

Pada tingkat LPH di atas 3\% diporoleh tingkat produksi yang baik (good level). Pertumbuhan pada musim produktif berkisar 50-95 kg/ris (Gambar 5a). Beberapa faktor yang berpengaruh terhadap pertumbuhan rumput laut adalah iklim dan lingkungan perairan seperti suhu, intensitas cahaya, dan salinitas (Kartono et al., 2008).

Salah satu indikator utama dalam mengidentifikasi musim produktif adalah pengukuran pertumbuhan dan analisis kualitas perairan (suhu dan salinitas). Pengukuran salinitas perairan berkorelasi terhadap tinggi rendahnya curah hujan. Data curah hujan tahun 2015 memperlihatkan bulan basah (Januari-Maret). Musim peralihan terjadi pada bulan Maret-Juni. Bulan kering terjadi pada bulan Juli hingga November yang ditandai dengan rendahnya curah hujan (Gambar 5b).

Musim produktif dengan produksi optimum terjadi pada bulan Juni hingga September. Terjadi peningkatan salinitas pada kisaran 33-35 ppt, yang disebabkan karena berkurangnya curah hujan. Kisaran ini masih mendukung pertumbuhan E. striatum, karena jenis ini tidak dapat tumbuh pada salinitas di bawah 24 ppt atau di atas 45 ppt (Parenrengi \& Sulaeman, 2007).

Pada musim non-produktif rata-rata produksi hanya mencapai $5-40 \mathrm{~kg} / \mathrm{ris}$ dan nilai salinitas cenderung menurun (30-32 ppt) (Gambar 5c). Hal ini terjadi pada awal (siklus-1) dan akhir pemeliharaan (siklus-7). Pada bulan Januari-Maret dan Desember memasuki musim penghujan dan terjadinya banjir (Gambar 5b).

Tingginya curah hujan menyebabkan turunnya salinitas hingga 29-30 ppt, yang berakibat banyak rumput laut yang mati. Kematian rumput laut akibat terganggunya proses osmoregulasi yang membuat talus menjadi rapuh dan rontok (Radiarta et al., 2013).

Air hujan dari daratan dengan salinitas yang lebih rendah akan mendorong dan menyebar secara horizontal ke arah laut (Maharani et al., 2014). Hal ini yang menyebabkan rumput laut yang dibudidaya secara longline di permukaan air akan rentan terkena dampak banjir. 

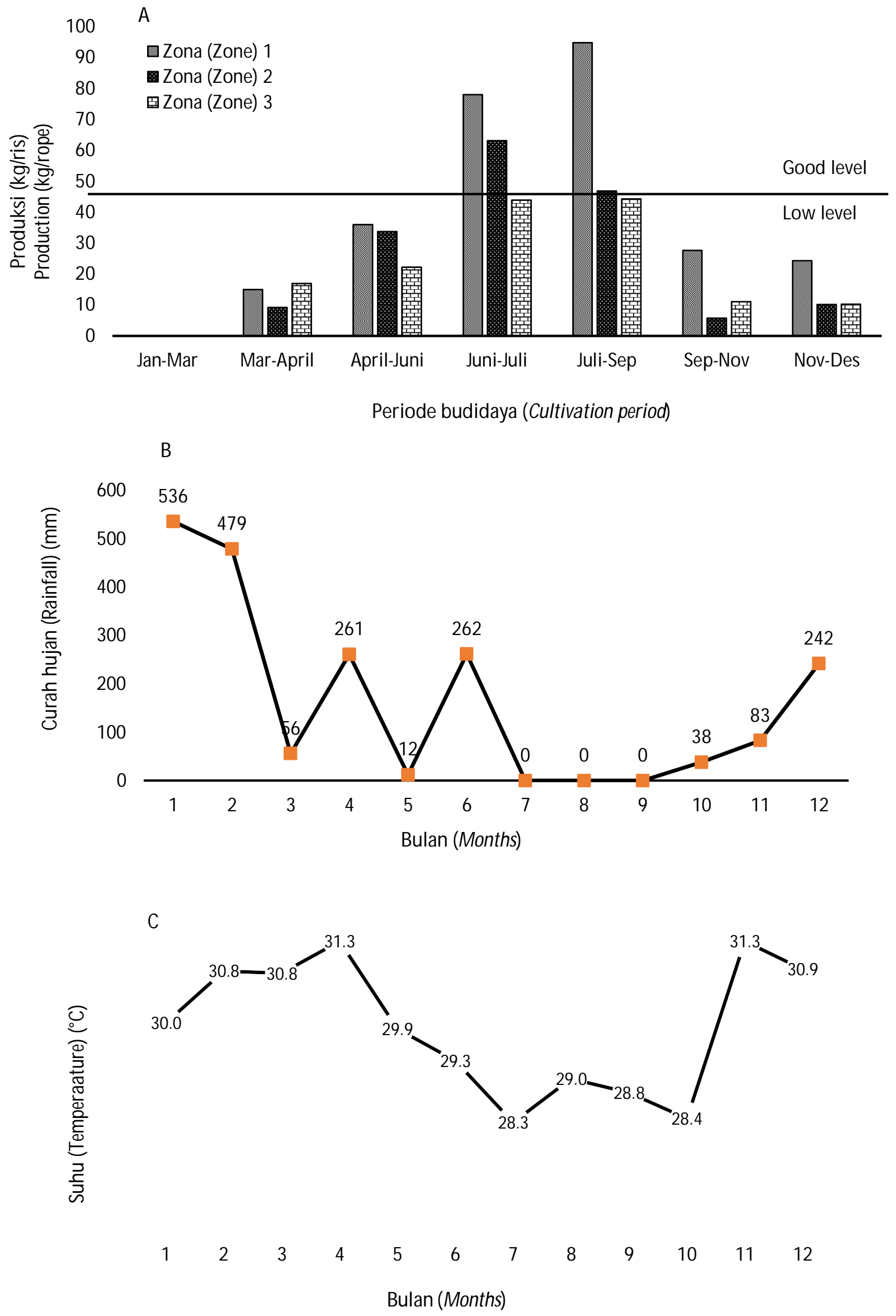


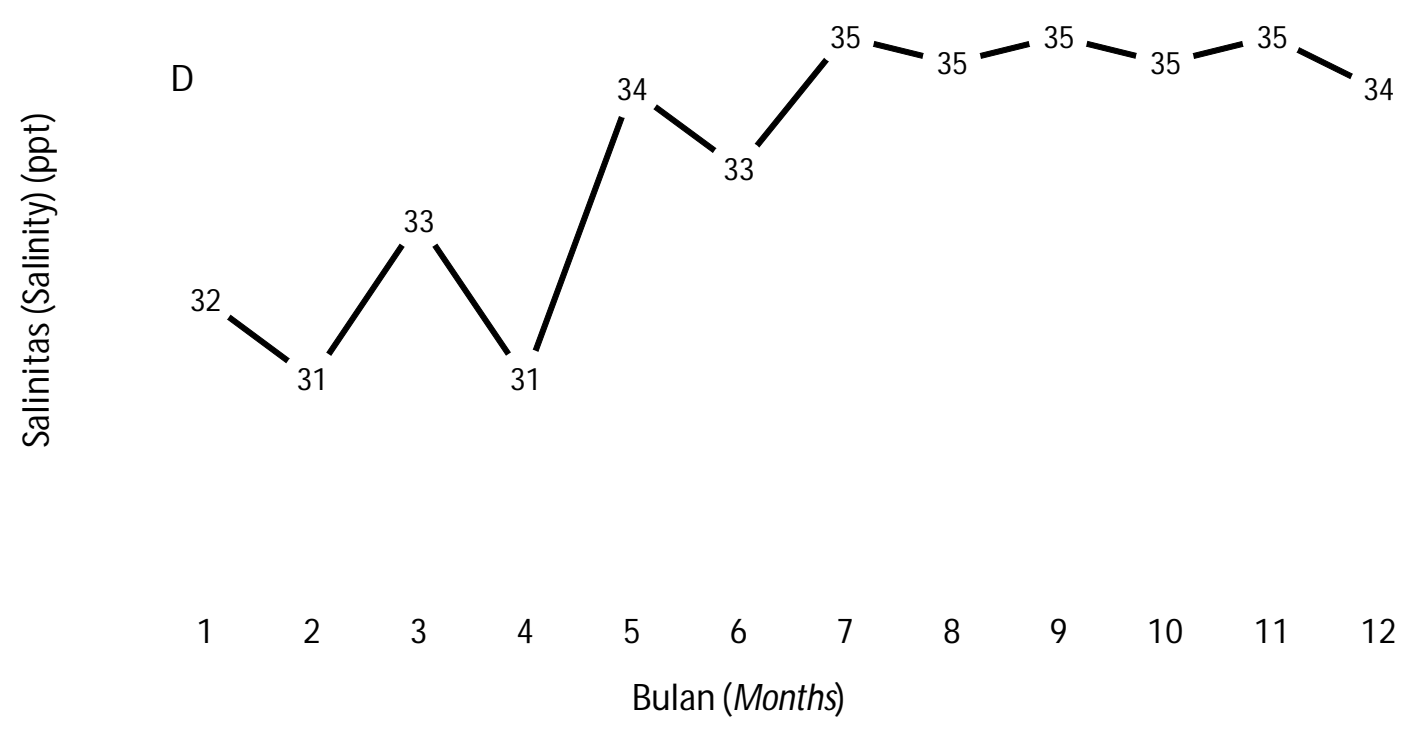

Gambar 5. Produksi rumput laut basah pada tiga zona di perairan Teluk Langge, Gorontalo Utara (a), informasi curah hujan (Stasiun BMKG Anggrek, Gorontalo Utara) pada tahun 2015 (b), salinitas perairan selama satu tahun pengamatan (c), suhu perairan satu tahun pengamatan (d).

Figure 5. Wet seaweed production at three zones in Langge Bay area, North Gorontalo (a), rainfall information (Anggrek Port Station, North Gorontalo) in 2015 (b), A yearly salinity variation at Langge Bay, (c), value of water temperature in one year at Langge Bay (d).

Aliran hujan dari daratan membawa material-material yang menyebabkan air laut menjadi keruh. Dampaknya banyak rumput laut yang mati/jatuh akibat tertutup lumpur. Aktivitas manusia seperti pengolahan lahan mengakibatkan adanya sedimentasi yang masuk ke badan air ketika terjadi adanya aliran air seperti hujan (Fransisca, 2011).

Pengukuran suhu perairan saat musim nonproduktif memperlihatkan peningkatan dengan kisaran $30^{\circ} \mathrm{C}-32^{\circ} \mathrm{C}$. Suhu pada musim produktif cenderung lebih rendah berkisar $28^{\circ} \mathrm{C}-30^{\circ} \mathrm{C}$ (Gambar $4 \mathrm{~d}$ ). Penurunan suhu disebabkan adanya hujan dengan intensitas rendah yang terjadi pada bulan Juni. Kisaran tersebut menurut Parenrengi \& Sulaeman (2007), masih mendukung untuk proses fotosintensis secara maksimum. Pertumbuhan rumput laut jenis Eucheuma dapat tumbuh dengan kisaran suhu antara $26^{\circ} \mathrm{C}-30^{\circ} \mathrm{C}$ (Anggadiredja et al., 2011).

Pengujian nitrat dan fosfat dilakukan pada bulan April hingga September (Gambar 6). Kandungan nitrat perairan mencapai $0,3 \mathrm{mg} / \mathrm{L}$ dan semakin menurun dengan kisaran 0,14-0,16 mg/L hingga di bulan September. Kandungan fosfat menunjukkan nilai tertinggi pada bulan Juni sebesar $2 \mathrm{mg} / \mathrm{L}$ dan mengalami penurunan pada kisaran $0,01 \mathrm{mg} / \mathrm{L}$ dan $0,08 \mathrm{mg} / \mathrm{L}$ pada bulan September.
Secara umum kisaran nitrat terendah untuk pertumbuhan alga yaitu 0,3-0,9 $\mathrm{mg} / \mathrm{L}$ dan untuk pertumbuhan optimum pada kisaran 0,91-3,5 mg/L (Effendi, 2003). Batas terendah konsentrasi fosfat untuk pertumbuhan rumput laut berkisar antara 0,018$0,090 \mathrm{mg} / \mathrm{L}$ apabila nitrogen dalam bentuk nitrat (Ambas, 2006).

Tingginya kandungan fosfat disebabkan adanya tambahan sumber alami fosfor di perairan yang bersumber dari dekomposisi bahan organik dari limbah dan domestik (Effendi, 2003), mengingat lokasi budidaya dekat dengan daratan sehingga diduga banyak buangan organik dan limbah dari daratan. Salah satunya adalah limbah domestik seperti deterjen yang merupakan limbah pemukiman paling potensial mencemari perairan. Limbah deterjen sangat sulit diuraikan oleh bakteri, sehingga mampu meningkatkan senyawa fosfat pada air yang dapat merangsang pertumbuhan ganggang (Fransisca, 2011).

Pengamatan indikator budidaya yang telah dilakukan selama satu tahun dapat disimpulkan menjadi satu informasi kalender musim tanam. Informasi parameter utama seperti produksi, serangan ice-ice atau teritip, musim penghujan, dan musim kemarau menjadi faktor penting. 


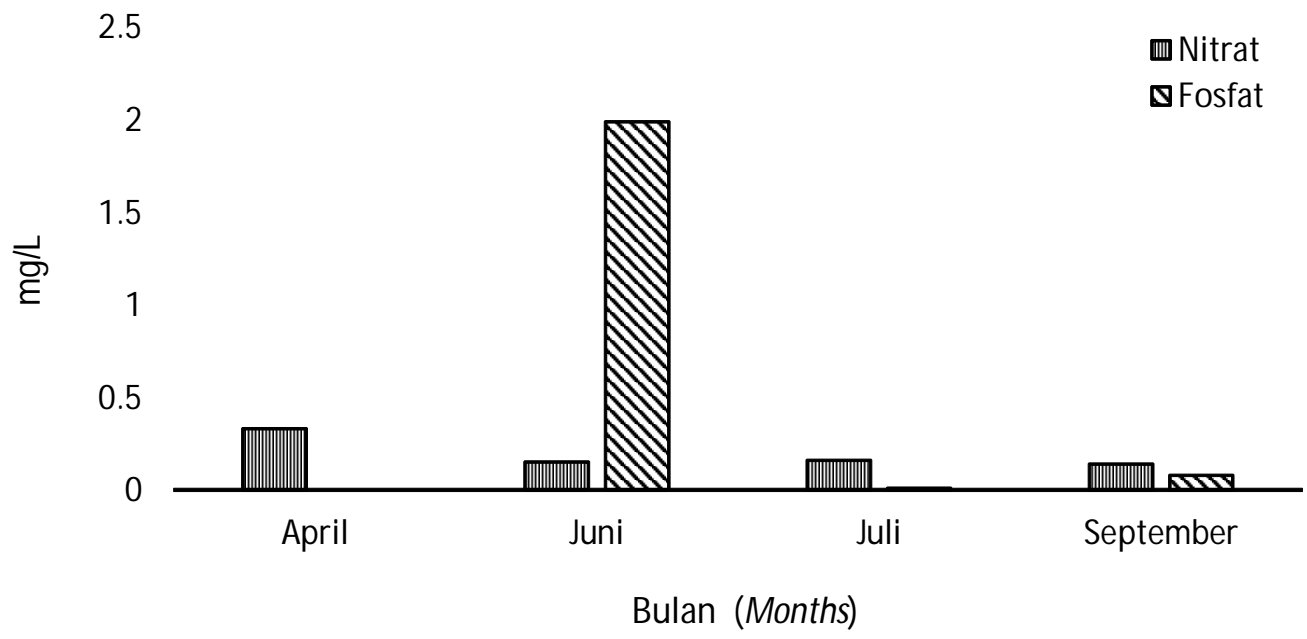

Gambar 6. Kandungan nitrat dan fosfat pada musim produktif di tiga lokasi pengamatan perairan Teluk Langge, Gorontalo Utara.

Figure 6. Nitrate and phosphate concentrations during the productive season in Langge Bay area, North Gorontalo.

Tabel 1. Musim tanam E. striatum di Teluk Langge tahun 2015, Gorontalo Utara

Table 1. Planting period of E. striatum in Langge Bay in 2015, North Gorontalo

\begin{tabular}{|c|c|c|c|}
\hline \multirow{2}{*}{$\begin{array}{l}\text { Lokasi } \\
\text { Location }\end{array}$} & \multirow{2}{*}{$\begin{array}{l}\text { Parameter } \\
\text { Parameters }\end{array}$} & Bulan (Months) & \multirow{2}{*}{$\begin{array}{c}\text { Pemecahan masalah } \\
\text { Problem solution }\end{array}$} \\
\hline & & $\begin{array}{lllllllllllll}1 & 2 & 3 & 4 & 5 & 6 & 7 & 8 & 9 & 10 & 11 & 12\end{array}$ & \\
\hline \multirow{6}{*}{$\begin{array}{l}\text { Teluk Lange } \\
\text { Lange Bay }\end{array}$} & $\begin{array}{l}\text { Epifit/suspensi } \\
\text { Epiphytes/suspension }\end{array}$ & & $\begin{array}{l}\text { Tali bentangan dibersihkan dan } \\
\text { digoyangkan } \\
\text { Cleaned and rocked long line rope }\end{array}$ \\
\hline & $\begin{array}{l}\text { Penyakit ice-ice } \\
\text { Iceice disease }\end{array}$ & & $\begin{array}{c}\text { Pilihlah bibit yang tahan terhadap } \\
\text { penyakit } \\
\text { atau lakukan istirahat tanam } \\
\text { Choose disease resistant seed or } \\
\text { planting breaks for a while }\end{array}$ \\
\hline & $\begin{array}{l}\text { Gelombang tinggi } \\
\text { High wave/current }\end{array}$ & & $\begin{array}{c}\text { Melakukan rotasi tanam di wilayah } \\
\text { yang terlindung } \\
\text { dari gelombang tinggi } \\
\text { Move to rather sheltered location }\end{array}$ \\
\hline & $\begin{array}{l}\text { Musim hujan } \\
\text { Rainy season }\end{array}$ & & $\begin{array}{c}\text { Melakukan rotasi tanam ke tempat } \\
\text { yang jauh dari muara/daratan serta } \\
\text { menurunkan bentangan hingga } \\
\text { kedalaman } 50 \mathrm{~cm} \\
\text { Move long line rope to distant place } \\
\text { from estuary and lowering the long } \\
\text { line rope to a depth } 50 \mathrm{~cm} \text { from the } \\
\text { water surface }\end{array}$ \\
\hline & $\begin{array}{l}\text { Musim kemarau } \\
\text { Dry season }\end{array}$ & & $\begin{array}{l}\text { Melakukan rotasi tanam ke tempat } \\
\text { yang dekat dari muara/daratan } \\
\text { serta menurunkan bentangan } \\
\text { hingga kedalaman } 50 \mathrm{~cm} \\
\text { M ove long line rope to a spot close to } \\
\text { estuary and lowering the long line } \\
\text { rope to a depth } 50 \mathrm{~cm} \text { from the water } \\
\text { surface } \\
\end{array}$ \\
\hline & $\begin{array}{l}\text { Musim produktif E. striatum } \\
\text { Productive season of E. striatum }\end{array}$ & & $\begin{array}{l}\text { Optimalkan bentangan budidaya } \\
\text { Optimize cultivation }\end{array}$ \\
\hline
\end{tabular}


Identifikasi parameter selama tahun 2015 di Teluk Langge menunjukkan musim produktif $(\mathrm{LPH}<3 \% \mathrm{E}$. striatum di atas 3\%hari terjadi pada bulan Juni hingga September (Tabel 1). Jumlah kemunculan serangan iceice sebanyak lima kejadian pada bulan April-Mei dan Oktober-Desember. Musim penghujan terjadi dari bulan Januari-April dan musim kemarau pada bulan MeiNovember.

Pengamatan selama budidaya cukup tinggi penempelan epifit dan sedimen, pada talus. Jenis $E$. striatum memiliki morfologi yang cukup unik dengan bentuk talus agak membulat dengan banyak percabangan dan padat (Anggadiredja et al., 2011). Hal inilah yang menyebabkan saat pemeliharaan sedimen dan epifit yang menempel pada talus susah untuk dibersihkan. Pengamatan morfologi secara umum memperlihatkan rumput laut yang dibudidaya dekat dengan daratan memiliki talus yang lebih besar dan berwarna lebih gelap.

Data informasi yang terdapat dalam kalender musim tanam bersifat dinamis dan dapat diperbaharui sesuai dengan perkembangan teknologi budidaya dan perubahan cuaca. Informasi kesesuaian lahan budidaya merupakan faktor penting yang perlu diperhatikan untuk mendukung keberhasilan di setiap kawasan budidaya rumput laut (Radiarta et al., 2013).

\section{KESIMPULAN}

Musim produktif rumput laut E. striatum di perairan Teluk Langge terjadi pada bulan Juni hingga September. Pertumbuhan rumput laut terbaik pada kawasan budidaya yang dekat dengan daratan.

\section{UCAPAN TERIMA KASIH}

Penulis mengucapkan terima kasih kepada seluruh tim kegiatan riset data informasi LRBRL, Dinas Kelautan dan Perikanan Kabupaten Gorontalo Utara, dan kelompok pembudidaya di Teluk Langge yang telah membantu dalam pengumpulan informasi dan kelengkapan data di lapangan. Penelitian ini sepenuhnya dibiayai oleh DIPA LRBRL T.A 2015.

\section{DAFTAR ACUAN}

Anggadiredja, J.T., Zatnika, A., Purwoto, H., \& Istini, S. (2011). Rumput laut: pembudidayaan pengolahan, dan pemasaran komoditas perikanan potensial. Jakarta: Penebar Swadaya.

Ambas, I. (2006). Budidaya rumput laut. Pelatihan Budidaya Laut Coremap Tahap II Kabupaten Selayar. Yayasan Mattirotasi, Makasar.

Badan Pusat Statistik Kabupaten Gorontalo Utara. (2014). Gorontalo Utara dalam angka 2014. BPS Gorontalo.
Effendi, H. (2003). Telaah kualitas air bagi pengelolaan sumber daya dan lingkungan perairan. Kanisius, Yogyakarta.

Erlania, \& Radiarta, I N. (2014). Perbedaan musim tanam terhadap performa budidaya empat varian rumput laut Eucheumatoids di Teluk Gerupuk, Nusa Tenggara Barat. Jurnal Riset Akuakultur, 9(2), 331342.

Fransisca, A. (2011). Tingkat pencemaran perairan ditinjau dari pemanfaatan ruang di wilayah pesisir Kota Cilegon. Jurnal Perencanaan Wilayah dan Kota, 22(2), 145-160.

Hurtado, A.C., \& Agbayani, R.F. (2000). The farming of seaweed Kappaphycus. Extention manual 32, SEAFDEC, Philippines.

Kamuli, S. (2014). Evaliasi tentang implementasi kebijakan pengembangan kawasan minapolitan di Kabupaten Gorontalo Utara. M imbar, 3(1), 43-61.

Kartono, I., Sutimin. M., \& Insani, D. (2008). Analisis model dinamik pertumbuhan biomassa rumput laut Gracilaria verrucosa. Forum Jurnal Matematika, Jurusan Matematika, Universitas Diponegoro, Semarang.

Maharani, R.W., Setiyono, H., \& Setyawan, B.W. (2014). Studi distribusi suhu, salinitas, dan densitas secara vertikal dan horizontal di perairan pesisir Probolinggo, Jawa Timur. Jurnal Oseanografi, 3(2), 151-160.

Nurdjana, M.L. (2006). Pengembangan budi daya rumput laut di Indonesia. Dalam Diseminasi Teknologi dan Temu Bisnis Rumput Laut. Badan Riset Kelautan dan Perikanan, Jakarta.

Parenrengi, A., \& Sulaeman. (2007). Mengenal rumput laut, Kappaphycus alvarezii. Media Akuakultur, 2(1), 142-146.

Pong-Masak, P.R. (2015). Standar operasional prosedur: pengembangan kebun bibit pada kawasan budidaya rumput laut. Loka Riset Budidaya Rumput Laut, Gorontalo.

Radiarta, I N., Erlania, \& Rusman. (2013). Pengaruh iklim terhadap musim tanam rumput laut Kappaphycus alvarezii di Teluk Gerupuk, Kabupaten Lombok Tengah, Nusa Tenggara Barat. Jurnal Riset Akuakultur, 8(3), 453-456.

Santoso, L., \& Nugraha, Y.T. (2008). Pengendalian penyakit ice-ice untuk meningkatkan produksi rumput laut Indonesia. Jurnal Saintek Perikanan, $3(2), 37-43$.

Utomo, B.S.B. (2011). Prospek pengembangan teknologi pengolahan rumput laut di Indonesia. Forum Inovasi Teknologi Akuakultur. Jakarta, Indonesia: Pusat Penelitian dan Pengembangan Perikanan Budidaya. Kementerian Kelautan dan Perikanan, hlm. 1143-1152. 